\title{
The Other 45: Improving Patients' Chronic Disease Self-Management and Medical Students' Communication Skills
}

Alexis M. Stoner, MPH, PhD; Matthew Cannon, DO; Liang Shan, PhD; Deanna Plewa, OMS IV; Claire Caudell, OMS IV; Luke Johnson, OMS IV

From the Edward Via College of Osteopathic Medicine-

Carolinas Campus in Spartanburg, South Carolina (Drs Stoner and Cannon and

Student Doctors Plewa, Caudell, and Johnson); and the University of Alabama at

Birmingham School of Medicine (Dr Shan).

Financial Disclosures:

None reported.

Support: This study was funded by the Edward Via

College of Osteopathic Medicine Research Eureka

Accelerator Program.

Address correspondence to Alexis M. Stoner, MPH, PhD,

Edward Via College of

Osteopathic Medicine-

Carolinas Campus, 350

Howard St, Spartanburg, SC 29303-3515.

Email: astoner@carolinas. vcom.edu

Submitted

May 18, 2018;

final revision received

August 9, 2018;

accepted

August 24, 2018.
Context: To improve chronic disease self-management among an underserved population and to improve the skills of second-year osteopathic medical students, an educational curriculum, The Other 45, was developed. In addition to a typical 15-minute office visit, this program allows second-year students to provide chronic disease education to patients for 45 minutes in an effort to improve patient disease self-management and associated health outcomes.

Objective: To determine whether patients who participate in The Other 45 report improvements in their ability to manage their chronic disease(s) and their health outcomes and whether second-year osteopathic medical students report changes in patient-centered care, clinical confidence, and medical/teaching knowledge.

Methods: Patients with a previously diagnosed chronic disease participated in 3 visits for The Other 45. Chronic disease self-management and health outcomes were measured using the Health Education Impact Questionnaire, which participants completed at each visit. Students received a formal presentation on teaching skills, and those who participated in The Other 45 completed a pre- and postclinic survey measuring 3 focused domains: patient-centered care, clinical confidence, and medical/teaching knowledge.

Results: A total of 47 patients and 69 students participated in the study. As measured by the Health Education Impact Questionnaire, patients' skill and technique acquisition $(P=.01)$, constructive attitudes and approaches $(P=.01)$, and health services navigation $(P=.03)$ showed significant improvement at the 3-week follow-up visit, and self-monitoring and insight showed significant improvement $(P=.01)$ at the 3-month follow-up visit. Patients' positive and active engagement in life $(P=.04$ and $P=.03)$ and emotional well-being $(P=.003$ and $P=.0007)$ significantly improved at the 3-week and 3-month follow-up, respectively. The students improved significantly in all 3 domains as a result of participating in the program: patient-centered care $(P=.012)$, clinical confidence $(P<.001)$, and medical/teaching knowledge $(P=.002)$.

Conclusions: The Other 45 was effective in improving patients' ability to manage their chronic disease(s), as well as improving second-year osteopathic medical students' ability to educate a patient with chronic disease. Implementing this type of program has the potential to affect patients with chronic disease as well as medical students in a rural underserved setting.

J Am Osteopath Assoc. 2018;118(11):703-712

doi:10.7556/jaoa.2018.155

Keywords: chronic disease, lifestyle medicine, patient education 


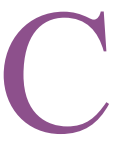

hronic conditions such as heart disease, cancer, diabetes, and chronic lower respiratory tract disorders represent the greatest disease burden in the United States. ${ }^{1}$ According to 2014 estimates, more than half of US adults have 1 chronic disease, and 4 in 10 US adults have more than 1 chronic disease. ${ }^{2}$ Additionally, persons with chronic disease face a greater financial toll and limitations in quality of life. ${ }^{2}$ According to 2014 Centers for Disease Control and Prevention data, ${ }^{3}$ in $2010,86 \%$ of all health care spending was on patients with 1 or more chronic medical conditions.

Chronic diseases are attributed in part to modifiable behavior risk factors such as obesity, tobacco use, poor diet, and physical inactivity. Although health care professionals play a key role in helping patients manage their diseases, the role of patients in their disease management is highly influential in long-term health outcomes and quality of life. Self-management is defined as "the individual's ability to manage the symptoms, treatment, physical and psychosocial consequences, and lifestyle changes inherent in living with a chronic condition." ${ }^{, 4}$ Many education and self-management programs have been implemented to target modifiable behavior risk factors to reduce the incidence of disease and improve chronic disease management. ${ }^{5-9}$ As a result of these programs, there is evidence to suggest that educational programs improve health literacy and health outcomes among patients with chronic diseases, including diabetes, rheumatoid arthritis, and coronary artery disease. Furthermore, educational programs supported by physicians and other health care professionals are especially effective for underserved populations. ${ }^{10}$

As medical students train to be physicians, developing their skills to effectively communicate and provide patient-centered care will be essential in helping them improve their patients' chronic disease selfmanagement. Developing a student's ability to teach has been shown to be an effective strategy to help them better acquire and apply knowledge. ${ }^{11}$ However, medical school curricula do not typically include training on formal education and teaching principles, and, often, medical students enter residency without confidence in their teaching abilities. ${ }^{12}$ Additionally, having a high level of confidence as a student is essential to a future physician's ability to communicate with patients. ${ }^{13}$ Giving students the opportunity to talk to patients and teach them about diseases has been shown to increase medical students' confidence in their level of medical knowledge and ability to provide patientcentered care. ${ }^{13}$ Evidence has shown that third-year students taking the time to talk to their patients and discuss their disease states had a positive impact on the students' views of patient-centered care and their understanding of patients' health states. ${ }^{14}$ Other research has suggested that medical students who participate in a formal teaching program have improved attitudes and ability to provide patient-oriented communication. ${ }^{15}$

To improve the level of knowledge and chronic disease self-management among an underserved population and improve the skills of second-year medical students, an educational curriculum, The Other 45, was developed at the Edward Via College of Osteopathic Medicine. This program works to address disease prevention, health literacy, patient compliance, disease management, and patient-physician communication. Typically, a physician is given 15 minutes to conduct a medical interview, perform a physical examination, provide a diagnosis, prescribe treatment, and document the medical encounter. This period often does not leave the physician enough time to ensure that patients have adequate comprehension of their medical condition and an understanding of how to manage their health in the best way possible. The Other 45 allows patients with a chronic medical condition to meet with a second-year osteopathic medical student for an additional 45 minutes to discuss their diagnosis, prescriptions, and other preventive health measures that aim to improve patients' health outcomes. Additionally, medical students can experience the patient-physician relationship first-hand, taking the time to actively listen to patients in order to effectively understand the personal obstacles or challenges they may be facing and appropriately counsel them in 
laymen's terms. It also helps students understand the importance of good communication and patient education. Teaching another person gives students a more complete understanding of their medical knowledge.

This study sought to determine whether patients who participate in The Other 45 show improvements in their ability to manage their chronic disease(s) and certain health outcomes. Additionally, it sought to determine whether participation would affect students' patientcentered care, clinical confidence, and medical/teaching knowledge.

\section{Methods}

This study implemented an exploratory, longitudinal study design using a convenience sample of medically underserved patients and second-year osteopathic medical students who self-selected to participate. This study was approved by the institutional review board of the Edward Via College of Osteopathic Medicine.

\section{The Other 45}

An educational curriculum developed by a collaborative team of osteopathic medical faculty and students, The Other 45 was conceptualized based on the results of a needs assessment conducted throughout the community that resulted in both qualitative and quantitative data indicating a need for education among patients with chronic disease. The program was originally piloted at a free clinic and based on formative evaluation adjusted to better meet the needs of the population and students. The program was officially implemented as part of the Early Clinical Experience curriculum at an osteopathic medical school during the 2016-2017 academic year at 3 different locations, including 2 free medical clinics and 1 Federally Qualified Health Center (FQHC). Patients scheduled for the Other 45 met 1 on 1 with a second-year osteopathic medical student either immediately after a scheduled appointment with their physician or for 1 of 2 follow-up appointments if they were participating in the program. To help standardize the program, 3 scripts were devel- oped for the chronic conditions targeted in this study (COPD, diabetes, and hypertension). Content for the scripts was derived from evidence-based sources and then validated by 2 physicians. These scripts were used to help guide the discussion between the student and the patient. In addition, The Other 45 was overseen by a faculty member at each of the 3 sites. Immediately after The Other 45 session, the student met with the overseeing faculty member to discuss the encounter, brainstorm goals, and reflect on the experience. The student also provided a written record of the session in the patient's medical record to provide continuity for the physician and follow-up sessions of The Other 45 .

\section{Participants}

Patients

Two methods were used to recruit patients. One method involved reviewing medical records, whereby patients with a diagnosis of COPD, diabetes, or hypertension were contacted via telephone and scheduled for The Other 45. The other method involved selecting patients with an existing appointment after which The Other 45 could be implemented at the clinic site. If they met the inclusion criteria, patients were referred by their physician to The Other 45 program, participating immediately after the appointment. Patients were eligible to participate if they had a diagnosis of COPD, diabetes, or hypertension; were aged 18 years or older; could speak and understand English; were able to read and complete the questionnaire; and had a life expectancy greater than 6 months. All patient participants were asked to read and sign an informed consent document Participating in the research included attending 3 visits for The Other 45 (initial visit, 3-week follow-up, and 3-month follow-up). Patients who attended all 3 scheduled appointments were provided a gift card as compensation as agreed upon during the informed consent process.

\section{Students}

All currently enrolled second-year osteopathic medical students who were scheduled to participate in The 
Other 45 (120 students) were eligible and recruited to participate in the study. Each Friday during the Early Clinical Experience Curriculum Calendar (mid-October through April), 3 groups of 2 students were sent to 1 of the 3 underserved clinic sites participating in The Other 45. Before their assigned clinic day, students were given a formal presentation on proper teaching principles. One week before the scheduled day, the students received a recruitment email asking them to participate in the research by completing a pre- and postclinic survey based on their experience in The Other 45. Informed consent was obtained via the survey. The email included the hyperlink to the preclinic survey and a reminder to complete the postclinic survey. After their clinical experience, the students received an email with a link to the postclinic survey to be completed within 48 hours.

\section{Measurement Tools}

Patients

\section{Health Education Impact Questionnaire}

Participants completed the Health Education Impact Questionnaire (HeiQ) at each of the 3 visits. ${ }^{16}$ The HeiQ is a patient-reported outcomes measurement tool that can evaluate chronic disease educational programs. It includes 40 items that comprise 8 constructs: positive and active engagement in life, health-directed behavior, skill and technique acquisition, constructive attitudes and approaches, self-monitoring and insight, health services navigation, social integration and support, and emotional well-being. ${ }^{16}$ A license to use the survey was obtained. This tool has been used both nationally and globally and is one of the most widely used evaluation tools for health education and self-management programs.

\section{Health Outcome Evaluation}

Participants with COPD completed the Clinical COPD Questionnaire (CCQ) to measure symptoms associated with their disease at each of the 3 visits. For participants with diabetes, hemoglobin $\mathrm{A}_{1 \mathrm{c}}$ was measured during the initial visit and at the 3-month follow-up visit. During each of the 3 visits, blood pressure was recorded for all participants.

\section{Students}

Before and after participating in The Other 45, the students' perception of patient-centered care, clinical confidence, and medical/teaching knowledge were measured via a survey from a previously validated tool that was adapted for the needs of this study. ${ }^{13}$ Because this survey is distributed under the Creative Commons License, the first 2 domains of the survey were obtained directly from this resource, and the third domain was created independently. The domain of perception of patient-centered care focused on aspects such as the patient-physician relationship and treatment plans that coincide with patients' personal values. The second domain measured confidence in dealing with ethical dilemmas, seeing patients independently, relating to a diverse patient population, being a self-reflective practitioner, explaining medical information to patients, contributing to patient care, and describing the natural history of an illness over time. The third domain measured students' confidence in their medical knowledge and understanding of COPD, diabetes, and hypertension, as well as their ability to effectively and appropriately explain medical conditions to a patient in a clinical setting.

\section{Statistical Analysis \\ Patients}

The primary outcome of this study was the results of the HeiQ. Each of the 8 constructs has 4 to 7 items that include a 4-point Likert-type scale (1=strongly disagree to $4=$ strongly agree). A higher score indicates better self-management except for the construct of emotional distress, which is measured by a reverse scale. For each construct, the mean value of the respective group of items was calculated at baseline, the 3-week follow-up visit, and the 3-month follow-up visit. Paired $t$ tests were used to compare the baseline and follow-up scores. Because this was an exploratory study, a significance level of $\alpha=.05$ and power of 0.8 were used to demonstrate a difference between the samples. 


\section{Students}

The student survey included a 5-point Likert-type scale ( $1=$ strongly disagree to $5=$ strongly agree). Each question was compared between pre- and postclinic surveys using the sign test, and then questions were grouped within the 3 major domains: patient-centered care, clinical confidence, and medical/teaching knowledge. The difference in mean scores between the pre- and postclinic survey results were analyzed using paired $t$ tests.

\section{Results}

A total of 47 patients and 69 students participated in this study. The majority of the patient population was

Table 1.

Demographics of Patients Who Participated in a Chronic Disease Self-Management Program (n=47)

\begin{tabular}{|c|c|}
\hline haracteristic & No. (\%) \\
\hline \multicolumn{2}{|l|}{ Gender } \\
\hline Male & $14(29.8)$ \\
\hline Female & $33(70.2)$ \\
\hline \multicolumn{2}{|l|}{ Age, y } \\
\hline $18-40$ & $4(8.5)$ \\
\hline $41-50$ & $6(12.8)$ \\
\hline $51-60$ & $24(51.06)$ \\
\hline $61-70$ & $10(21.3)$ \\
\hline$>70$ & $3(6.4)$ \\
\hline \multicolumn{2}{|l|}{ Education } \\
\hline$<$ High school diploma & $4(8.5)$ \\
\hline High school graduate & $26(55.3)$ \\
\hline Some college & $8(17.0)$ \\
\hline College graduate & $4(8.5)$ \\
\hline Missing & $5(10.6)$ \\
\hline \multicolumn{2}{|l|}{ Clinic Location } \\
\hline Free clinic 1 & $11(23.4)$ \\
\hline Free clinic 2 & $11(23.4)$ \\
\hline FQHC & $25(53.2)$ \\
\hline
\end{tabular}

Abbreviation: FQHC, Federally Qualified Health Center. female $(30[70 \%])$, with a mean age of 55.5 years (Table 1). The highest education level attained by most patients was a high school diploma (26 [55.3\%]). Twenty-two patients $(46.8 \%)$ were seen at a free clinic and 25 (53.2\%) were seen at the FQHC. Student demographics were not analyzed.

\section{HeiQ Scale}

Based on the paired $t$ test results of the 8 HeiQ scales measured, 3 patients showed significant improvement from baseline to the 3-week follow-up visit: skill and technique acquisition $(P=.01)$, constructive attitudes and approaches $(P=.01)$, and health services navigation $(P=.03)$ (Table 2). Although these same scales did not show a significant change from baseline to the 3-month follow-up visit, they also showed no significant change from the 3-week follow-up visit to the 3-month follow-up visit, indicating that they maintained the level of improvement from the second to the third visit. Self-monitoring and insight showed significant improvement $(P=.01)$ from baseline to the 3-month follow-up visit (Table 2). Two scales indicated significant improvement from baseline to the 3-week follow-up visit and from baseline to the 3-month follow-up visit, respectively: positive and active engagement in life $(P=.04$ and $P=.03)$ and emotional well-being $(P=.003$ and $P<.001)$ (Table 2).

\section{Health Outcome Measurements}

Because of the small number of patients with COPD enrolled $(n=5)$, no statistical test was performed for changes found in the CCQ results. However, an overall decreasing trend in the mean score was found across all 3 visits (Table 3 ). While there was also a decreasing trend in the hemoglobin $\mathrm{A}_{1 \mathrm{c}}$ levels and systolic and diastolic blood pressure levels, no significant differences were found in the results of either measurement between baseline and the 3-month follow-up.

\section{Student Outcomes}

Significant improvement $(P=.012)$ was demonstrated in the first domain: students' self-reported ability to provide patient-centered care (Table 4). 


\section{Table 2.}

Patient Chronic Disease Self-Management Outcomes as Measured by the HeiQ (n=47)

\begin{tabular}{|c|c|c|c|c|c|c|c|c|c|c|}
\hline \multirow[b]{2}{*}{$\begin{array}{l}\text { HeiQ } \\
\text { Constructs }\end{array}$} & \multicolumn{5}{|c|}{ Baseline to 3-wk Follow-up $(n=35)$} & \multicolumn{5}{|c|}{ Baseline to 3-mo Follow-up $(n=26)$} \\
\hline & $\begin{array}{c}\text { Mean } \\
\text { Baseline }\end{array}$ & $\begin{array}{c}\text { Mean } \\
\text { Follow-up }\end{array}$ & $\begin{array}{c}\text { Mean } \\
\text { Change } \\
\text { From } \\
\text { Baseline }\end{array}$ & $\begin{array}{c}\text { Paired } \\
t \text { Test } \\
P \\
\text { Value }\end{array}$ & $\begin{array}{c}\mathbf{9 5 \%} \mathrm{CI} \text { of } \\
\text { Change } \\
\text { from } \\
\text { Baseline }\end{array}$ & $\begin{array}{c}\text { Mean } \\
\text { Baseline }\end{array}$ & $\begin{array}{c}\text { Mean } \\
\text { Follow-up }\end{array}$ & $\begin{array}{c}\text { Mean } \\
\text { Change } \\
\text { From } \\
\text { Baseline }\end{array}$ & $\begin{array}{c}\text { Paired } \\
\text { t Test } \\
P \\
\text { Value }\end{array}$ & $\begin{array}{c}95 \% \mathrm{Cl} \text { of } \\
\text { Change } \\
\text { From } \\
\text { Baseline }\end{array}$ \\
\hline $\begin{array}{l}\text { 1. Positive \& } \\
\text { active } \\
\text { engagement in } \\
\text { life }\end{array}$ & 3.07 & 3.27 & 0.2 & .04 & $\begin{array}{c}0.01 \text { to } \\
0.38\end{array}$ & 3.00 & 3.24 & 0.24 & .03 & $\begin{array}{c}0.03 \text { to } \\
0.45\end{array}$ \\
\hline $\begin{array}{l}\text { 2. Health- } \\
\text { directed activity }\end{array}$ & 2.71 & 2.84 & 0.13 & .28 & $\begin{array}{c}-0.11 \text { to } \\
0.37\end{array}$ & 2.73 & 2.78 & 0.05 & .75 & $\begin{array}{c}-0.26 \text { to } \\
0.35\end{array}$ \\
\hline $\begin{array}{l}\text { 3. Skill and } \\
\text { technique } \\
\text { acquisition }\end{array}$ & 3.09 & 3.33 & 0.24 & .01 & $\begin{array}{c}0.08 \text { to } \\
0.41\end{array}$ & 3.02 & 3.15 & 0.13 & $<.01$ & $\begin{array}{c}-0.09 \text { to } \\
0.36\end{array}$ \\
\hline $\begin{array}{l}\text { 5. Self- } \\
\text { monitoring and } \\
\text { insight }\end{array}$ & 3.11 & 3.30 & 0.19 & .07 & $\begin{array}{c}-0.01 \text { to } \\
0.40\end{array}$ & 3.09 & 3.35 & 0.26 & .01 & $\begin{array}{c}0.08 \text { to } \\
0.43\end{array}$ \\
\hline $\begin{array}{l}6 . \text { Health } \\
\text { service } \\
\text { navigation }\end{array}$ & 3.39 & 3.58 & 0.18 & .03 & $\begin{array}{c}0.02 \text { to } \\
0.35\end{array}$ & 3.38 & 3.43 & 0.05 & .57 & $\begin{array}{c}-0.14 \text { to } \\
0.24\end{array}$ \\
\hline $\begin{array}{l}\text { 7. Social } \\
\text { integration and } \\
\text { support }\end{array}$ & 3.13 & 3.32 & 0.19 & .12 & $\begin{array}{c}-0.05 \text { to } \\
0.44\end{array}$ & 3.05 & 3.20 & 0.15 & .17 & $\begin{array}{c}-0.07 \text { to } \\
0.38\end{array}$ \\
\hline $\begin{array}{l}\text { 8. Emotional } \\
\text { distress }\end{array}$ & 2.38 & 2.09 & -0.29 & .003 & $\begin{array}{c}-0.45 \text { to } \\
-0.12\end{array}$ & 2.49 & 2.23 & -0.26 & $<.001$ & $\begin{array}{c}-0.12 \text { to } \\
0.40\end{array}$ \\
\hline
\end{tabular}

Abbreviation: HeiQ, Health Education Impact Questionnaire.

Students reported a significant increase in the confidence in the clinical setting domain $(P<.001)$. All aspects of the confidence domain measured by this study showed statistically significant increases, with $P$ values ranging from $<.001$ to .004 (Table 4).

The third domain, students' medical/teaching knowledge, also showed significant increases between the pre- and postclinic survey results $(P=.002)$. The students' understanding of COPD, diabetes, and hypertension increased throughout the study, as did their ability to explain medical conditions to a patient in layman's terms. Notably, when questioned about the importance of gaining experience in the clinical setting as a secondyear medical student, students reported a significant increase ( $P=.003$ ). Additionally, the teaching principles PowerPoint (Microsoft) presentation attended by all students before participating in the study was noted to be beneficial $(P=.005)$ (Table 4$)$.

\section{Discussion}

The self-reported results of this study indicate that participating in The Other 45 significantly improves patients' ability to self-manage their chronic disease(s) 


\section{Table 3.}

Patient Health Outcome Results at Follow-up Visits in a Chronic Disease Self-Management Program

\begin{tabular}{|c|c|c|c|c|c|}
\hline Outcome Measure & $\begin{array}{c}\text { Mean } \\
\text { Baseline }\end{array}$ & $\begin{array}{l}\text { Mean 3-wk } \\
\text { Follow-up }\end{array}$ & P Value (95\% CI) & $\begin{array}{l}\text { Mean 3-mo } \\
\text { Follow-up }\end{array}$ & P Value $(95 \%$ CI) \\
\hline$C C Q^{a}$ & 23.6 & 22.4 & NA & 21.2 & NA \\
\hline Hemoglobin $\mathbf{A}_{1 \mathrm{c}}{ }^{\mathrm{a}}$ & 8.8 & NA & NA & 8.3 & 0.36 (0.95 to 0.48$)$ \\
\hline \multicolumn{6}{|c|}{ Blood Pressure, ${ }^{b} \mathrm{~mm} \mathrm{Hg}$} \\
\hline Systolic & 136.5 & 130.9 & $0.2(-12.6$ to 3.74$)$ & 130.04 & $0.23(-16.6$ to 7.1$)$ \\
\hline Diastolic & 83.3 & 81.3 & $0.16(-5.76$ to 1.76$)$ & 81.8 & $0.35(-6.55$ to 4.94$)$ \\
\hline
\end{tabular}

a No statistical test was performed because of the small sample size.

b Wilcoxon signed rank test for comparison of the means.

Abbreviation: CCQ, Clinical COPD [chronic obstructive pulmonary disease] Questionnaire; NA, not applicable.

and also enhances medical students' perceptions of their patient-centered care, clinical confidence, and medical/teaching knowledge. The 8 scales measured by the HeiQ varied in their results, highlighting the potential short-term and long-term benefits of the program. Positive and active engagement in life, skill and technique acquisition, and emotional distress all showed significant improvement at both the second and third follow-up visits. These findings suggest that multiple educational sessions can help improve patients' motivation to improve their life circumstances, provide skills to achieve symptomatic relief from their chronic disease, and reduce negative health-related affect, improving feelings such as stress, anger, depression, and anxiety. Constructive attitudes and approaches and health services navigation showed significant improvement at the first follow-up (3-week) visit, with improved differences maintained at the 3-month visit. This finding suggests that possibly 1 or 2 sessions in the program are necessary to help patients minimize the effects of the disease on daily life, improve their ability to communicate with health care professionals, and understand how to get their needs met within the health care system. Self-monitoring and insight was the only construct that only showed significant improvements at the 3-month visit, indicating that improving patients' abilities to monitor their own subclinical indicators of their disease may take longer involvement with a program and multiple educational sessions.

Other chronic disease self-management programs also found variation in changes across the scales measured by the HeiQ. ${ }^{17-20}$ It is difficult to make direct comparison with previous literature, as our population, sample size, and intervention differ greatly. It does appear that consistent with our study, in certain constructs patients were consistent in showing short-term changes (constructive attitudes and approaches) while in other constructs patients maintained longer-term improvements (skill and technique acquisition; positive and active engagement in live, emotional distress; and self-monitoring and insight). ${ }^{17-20}$

In all 3 domains measured, the second-year medical students showed significant improvement, with the greatest change in their confidence in a clinical setting. These results were similar to other studies. ${ }^{13}$ The moderate increase in patient-centered care may be attributed to students' increased awareness of the needs of patients after spending 45 minutes educating and teaching them. ${ }^{14}$ This experience improved patient-centered care and medical knowledge as reported by the students. These results may be attributed to the student being given an opportunity to participate in an experiential learning environment where they have the opportunity to directly interact with patients rather than a 


\section{Table 4.}

Second-Year Medical Student Survey Outcomes After Participating in a Chronic Disease Self-Management Patient Education Program ${ }^{a}$

\begin{tabular}{|c|c|c|c|}
\hline Domain and Items & Preclinic Score, Mean (SD) & Postclinic Score, Mean (SD) & $P$ Value \\
\hline Patient-Centered Care & $3.39(0.35)$ & $3.49(0.27)$ & .012 \\
\hline Patients equal to doctor & $4.09(1.040)$ & $4.30(0.896)$ & .061 \\
\hline Doctors asking questions & $1.77(0.877)$ & $1.70(0.649)$ & .192 \\
\hline Diagnosis vs treatment of patients & $4.04(0.848)$ & $4.14(0.845)$ & .132 \\
\hline Referring to patients as a diagnosis & $2.26(0.965)$ & $2.28(1.027)$ & .430 \\
\hline Treatment agrees with patients' values & $4.10(0.910)$ & $4.28(0.889)$ & .022 \\
\hline Long-term involvement in patient care & $4.54(0.609)$ & $4.59(0.652)$ & .143 \\
\hline Doctors advocate for patient needs & $4.67(0.533)$ & $4.65(0.564)$ & .577 \\
\hline Doctor decides discussion & $2.61(0.752)$ & $2.65(0.764)$ & .360 \\
\hline Disease management vs illness & $2.48(1.119)$ & $2.61(1.167)$ & .018 \\
\hline Clinical Confidence & $3.80(0.50)$ & $4.13(0.53)$ & $<.001$ \\
\hline Dealing with ethical dilemmas & $3.68(0.813)$ & $3.94(0.705)$ & .001 \\
\hline Seeing patients independently & $3.59(0.896)$ & $4.06(0.784)$ & $<.001$ \\
\hline Relating to diverse patients & $3.91(0.748)$ & $4.15(0.675)$ & .004 \\
\hline Being a self-reflective practitioner & $3.99(0.757)$ & $4.32(0.653)$ & $<.001$ \\
\hline Explaining medical information & $3.78(0.820)$ & $4.10(0.731)$ & $<.001$ \\
\hline Contributing to patient care & $3.94(0.725)$ & $4.30(0.692)$ & $<.001$ \\
\hline Describing history of an illness & $3.70(0.773)$ & $4.09(0.658)$ & $<.001$ \\
\hline Medical/Teaching Knowledge & $3.71(0.33)$ & $3.87(0.34)$ & .002 \\
\hline Understanding of COPD, DM, and hypertension & $4.01(0.469)$ & $4.20(0.558)$ & .001 \\
\hline Teaching PowerPoint beneficial & $3.61(0.752)$ & $3.87(0.784)$ & .005 \\
\hline Explaining information in layman's terms & $3.52(0.779)$ & $3.99(0.831)$ & $<.001$ \\
\hline Importance of clinical experience & $4.41(0.773)$ & $4.62(0.644)$ & .003 \\
\hline One-on-one patient time is uncomfortable & $2.25(0.864)$ & $1.93(0.810)$ & $<.001$ \\
\hline One-on-one patient time is beneficial & $4.51(0.656)$ & $4.59(0.626)$ & .115 \\
\hline
\end{tabular}

a Mean scores for each domain were compared using the paired $t$ test. Individual items within each domain were compared using the sign test.

Abbreviations: COPD, chronic obstructive pulmonary disease; DM, diabetes mellitus.

formal classroom learning environment. The significant increase in the students' confidence in the clinical setting is potentially due to the students being given a low-stress opportunity to interact with real patients with a much longer time limit than a normal clinic visit. Existing literature shows the importance of allow- ing students time to interact with patients before starting residency, and our findings indicate that The Other 45 is an important method through which this experience can be provided. ${ }^{12}$

Second-year osteopathic medical students are an excellent resource to bridge the gap between the short 
time a physician gets to spend with a patient and the patient's comprehension of his or her disease process. Within the standard model used by most physicians in the clinical setting, it is understood that 45-minute office visits are not practical. This study does not suggest that practicing physicians adopt this model or that students should plan to implement visits like these in their future practices. Rather, it demonstrates that patients' self-management of their chronic disease can improve with education, that second-year osteopathic medical students can significantly benefit in their confidence and medical knowledge when participating in these patient interactions, and that awareness of these factors can be used to enhance patient education and student education in the future.

An osteopathic approach to training medical students and delivering health care encompasses viewing the patient as a whole and addressing the patient's body, mind, and spirit. Through the Other 45, students were able to understand the value of listening to their patients and appropriately articulating medical knowledge. Students were also able to address their own mental, physical, and spiritual needs, which enhanced their actualization of the osteopathic philosophy. The Other 45 provides an opportunity for medical students to look beyond the biomedical condition and understand the barriers to health that these medically underserved patients faced, allowing students to help each patient address the individual variables that influenced their mind and spirit, which can have a large impact on chronic disease outcomes.

Although this study demonstrated significant positive results for both patients and students, there were limitations that should be noted. Transportation and scheduling conflicts resulted in a higher than expected loss to follow-up and lower patient sample size. Similar issues made it difficult for the patients to come exactly on the 3 -week or 3-month follow-up date. However, we strived to see them at least 2 weeks within the targeted time range. Future research should be conducted to measure longer-term health outcomes. Additionally, the program would benefit from including a control group to directly compare both health measurements and HeiQ construct outcomes. In addition, future studies should focus on measuring objective improvement in medical knowledge rather than subjective improvement.

\section{Conclusion}

As chronic disease rates will continue to rise and be the leading cause of death across the United States, it is imperative that patients are provided adequate support for self-management. As indicated in the literature and within this study, education has the potential to help patients improve across many constructs that affect their ability to best manage their diseases. Physicians are often the first line of support when patients receive a chronic disease diagnosis. Helping future physicians develop the tools to provide their patients knowledge and skills regarding their chronic disease is one method to help deliver this education. This study suggests that The Other 45 was effective in improving patients' self-reported outcomes, as well as improving future physicians' ability to relate to and educate their patients with chronic disease. Although the piloted program faced some logistical and support issues, implementing these types of programs has the potential to affect patients with chronic disease as well as medical students in a rural underserved setting.

\section{Author Contributions}

All authors provided substantial contributions to conception and design, acquisition of data, or analysis and interpretation of data; all authors drafted the article or revised it critically for important intellectual content; all authors gave final approval of the version of the article to be published; and all authors agree to be accountable for all aspects of the work in ensuring that questions related to the accuracy or integrity of any part of the work are appropriately investigated and resolved.

\section{References}

1. National Center for Chronic Disease Prevention and Health Promotion: about chronic diseases. Centers for Disease Control and Prevention website. https://www.cdc.gov/chronicdisease/about/index.htm. Accessed June 27, 2018.

2. Buttorff C, Ruder T, Bauman M. Multiple Chronic Conditions in the United States. Santa Monica, CA: RAND Corporation, 2017. 
3. Gerteis J, Iszrael D, Deitz D, et al. Multiple Chronic Conditions Chartbook. Rockville, MD: Agency for Healthcare Research and Quality, 2014

4. Barlow J, Wright C, Sheasby J, Turner A, Hainsworth J. Self-management approaches for people with chronic conditions: a review. Patient Educ Couns. 2002;48(2):177-187.

5. Adams RJ. Improving health outcomes with better patient understanding and education. Risk Manag Healthc Policy. 2010;3:61-72. doi:10.2147/RMHP.S7500

6. Effing $\mathrm{T}$, Monninkhof EM, van der Valk $\mathrm{P}$, et al. Self-management education for patients with chronic obstructive pulmonary disease. Cochrane Database Syst Rev. 2007;(4):CD002990.

7. Lee JY, Yoo KH, Kim DK, et al. Effects of educational interventions for chronic airway disease on primary care. J Korean Med Sci. 2016;31 (7):1069-1074. doi:10.3346/jkms.2016.31.7.1069

8. Ndosi M, Johnson D, Young T, et al. Effects of needs-based patient education on self-efficacy and health outcomes in people with rheumatoid arthritis: a multicentre, single blind, randomised controlled trial. Ann Rheum Dis. 2016;75(6):1126-1132. doi:10.1136/ annrheumdis-2014-207171

9. Omachi TA, Sarkar U, Yelin EH, Blanc PD, Katz PP. Lower health literacy is associated with poorer health status and outcomes in chronic obstructive pulmonary disease. J Gen Intern Med. 2013;28 (1):74-81. doi:10.1007/s11606-012-2177-3

10. Coulter A, Ellins J. Effectiveness of strategies for informing, educating, and involving patients. BMJ. 2007;335(7609):24-27. doi:10.1136 /bmj.39246.581169.80

11. Pasquale SJ, Pugnaire MP. Preparing medical students to teach. Acad Med. 2002;77(11):1175-1176.

12. Dandavino M, Snell L, Wiseman J. Why medical students should learn how to teach. Med Teach. 2007;29(6):558-565. doi:10.1080 /01421590701477449
13. McNair R, Griffiths L, Reid K, Sloan H. Medical students developing confidence and patient centredness in diverse clinical settings: a longitudinal survey study. BMC Med Educ. 2016;16(1):176 doi:10.1186/s12909-016-0689-y

14. Saba GW, Chou CL, Satterfield J, et al. Teaching patient-centered communication skills: a telephone follow-up curriculum for medical students. Med Educ Online. 2014;19:22522. doi:10.3402/meo. v19.22522

15. Choudhary A, Gupta V. Teaching communications skills to medical students: introducing the fine art of medical practice. Int J Appl Basic Med Res. 2015;5(suppl 1):S41-S44. doi:10.4103/2229-516X.162273

16. Osborne RH, Elsworth GR, Whitfield K. The Health Education Impact Questionnaire (heiQ): an outcomes and evaluation measure for patient education and self-management interventions for people with chronic conditions. Patient Educ Couns. 2007;66(2):192-201. doi:10.1016/j. pec.2006.12.002

17. Laursen DH, Christensen KB, Christensen U, Frølich A. Assessment of short and long-term outcomes of diabetes patient education using the Health Education Impact Questionnaire (HeiQ). BMC Res Notes. 2017;10(1):213. doi:10.1186/s13104-017-2536-6

18. Nolte S, Elsworth GR, Sinclair AJ, Osborne RH. The extent and breadth of benefits from participating in chronic disease self-management courses: a national patient-reported outcomes survey. Patient Educ Couns. 2007;65(3):351-360. doi:10.1016/j.pec.2006.08.016

19. Schuler M, Musekamp G, Bengel J, et al. Measurement of stable changes of self-management skills after rehabilitation: a latent statetrait analysis of the Health Education Impact Questionnaire (heiQ ${ }^{\mathrm{TM}}$ ). Qual Life Res. 2014;23(9):2531-2543. doi:10.1007/s11136-014-0693-9

20. Wahl AK, Langeland E, Larsen MH, Robinson H, Osborne R, Krogstad A-L. Positive changes in self-management and disease severity following climate therapy in people with psoriasis. Acta Derm Venereol. 2015;95(3):317-321. doi:10.2340/00015555-1939

(c) 2018 American Osteopathic Associatio 